\title{
Pericardial defect presenting as acute pericarditis
}

\author{
J. E. Carty, P. B. Deverall, and M. S. Losowsky \\ From the Department of Medicine, St. Fames's (University) Hospital, Leeds
}

A case of herniation of the left atrial appendage, through a defect in the pericardium, is described in a I6-yearold boy who was below the third percentile for height and weight. The clinical presentation was an acute pericarditis. Widespread inversion of $T$ waves on the electrocardiogram and collapse of the lower lobe of the left lung with pleural effusion developed. Thoracotomy showed strangulation of the atrial appendage which was excised, and the pericardial defect repaired. After operation there was a striking improvement in the electrocardiogram and a rapid gain in weight. Syndromes caused by pericardial defects are reviewed.

Herniation of the left atrium though a naturally occurring defect in the pericardium is an unusual lesion and few cases have been reported. We describe a patient with a hitherto unreported complication of this condition in whom the mode of presentation differed from previous reports. Diagnosis was more delayed and surgery was more clearly indicated.

\section{Case report}

A I6-year-old male apprentice chef had been well until one week before admission when he slowly developed dull, intermittent, retrosternal chest pain. This had gradually become worse and was accompanied by a dry cough. Twenty-four hours before admission the pain became constant, was eased by sitting forward, and made worse by deep inspiration and coughing. There were no other symptoms and he had been on no recent drug therapy. When ro years old he had been admitted to hospital after being run over by a car and at that time clinical examination had been normal. His childhood illnesses consisted only of measles and rubella.

On admission he was noted to be small (below the 3rd percentile for height and weight), mildly pyrexial $\left(38^{\circ} \mathrm{C}\right)$, and in moderate distress. There was no anaemia, dyspnoea, or cyanosis. Examination of the cardiovascular system showed that the pulse was regular, and of normal volume, blood pressure was $130 / 70 \mathrm{mmHg}$ : the jugular venous pressure was raised $2 \mathrm{~cm}$ above the sternal angle, the apex beat was palpable in the fourth left intercostal space and a left parasternal impulse was palpated. On auscultation, the first and second heart sounds were normal, there was an ejection systolic murmur at the left sternal edge, maximal on inspiration, and a pericardial friction rub over the whole praecordium. There was no ankle or sacral oedema.

A presumptive diagnosis of viral pericarditis was made.

\section{Investigations}

Hb $12.2 \mathrm{~g} / 100 \mathrm{ml}$; WBC 14,600: 77 per cent neutrophils, 2 I per cent lymphocytes, and 2 per cent monocytes; ESR $20 \mathrm{~mm}$ in I hour; serum electrolytes normal; urine deposit normal; antinuclear factor and DAT negative; plasma proteins: albumin $3.7 \mathrm{~g} / 100 \mathrm{ml}$, and globulin $2.6 \mathrm{~g} / 100 \mathrm{ml}$; electrophoretic strip showed a raised $\alpha_{2}-$ globulin; serum ASO titre normal.

Electrocardiogram (Fig. I) showed a broadened QRS complex in lead III. Six days later there was also $T$ wave inversion in lead $\mathrm{V} 2$ and isoelectric $T$ wave segments in leads V3-V6.

Chest $x$-ray (Fig. 2) initially showed haziness of the left diaphragm and a localized expansion of the cardiac outline in the region of the pulmonary conus; the vascular pattern of the lungs appeared normal. Tomography confirmed a dense projection from the left heart border; the main bronchi were patent and there was no evidence of glandular enlargement.

\section{Clinical course}

The white cell count remained raised throughout the patient's stay in hospital and the erythrocyte sedimentation rate rose to $45 \mathrm{~mm}$ in I hour. Three days after admission the pyrexia had resolved without treatment, and the pericardial friction rub had become localized to the left sternal edge. The patient was considerably improved and had only slight pain. Eight days after this he developed more severe pain in the left mammary area, exacerbated by respiration. At the time there was pronounced impairment of the percussion note and distant bronchial breathing at the base of the left lung. Chest $x$-ray showed collapse of the left lower lobe with a small pleural effusion and electrocardiogram showed $T$ wave inversion in leads I, II, III, and all the chest leads.

Twenty-three days after admission angiocardiography showed the mass at the left heart border to be a protrusion of the left atrium with a narrow neck. The constriction in this protrusion was presumed to be caused 


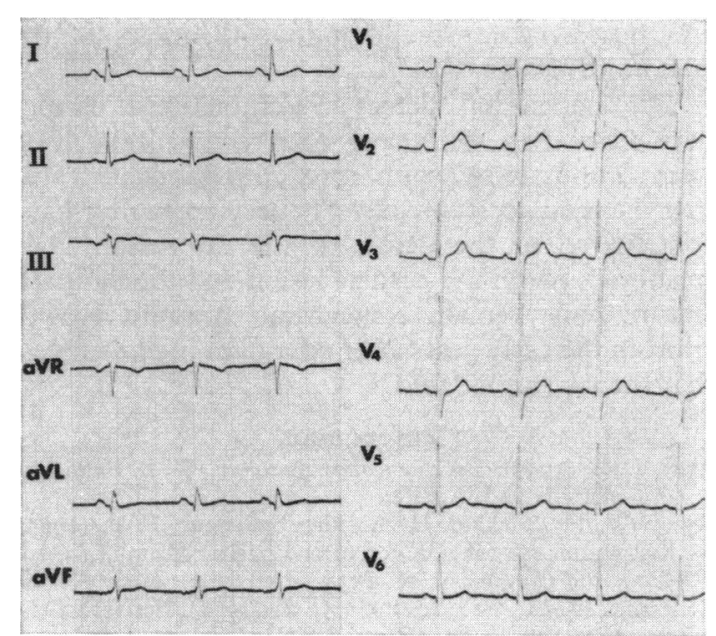

FIG. I Electrocardiogram on admission.

by the pericardium. Pressure studies showed no evidence of a valvular lesion.

Left thoracotomy was performed 13 days later. There was a moderate sized serosanguinous effusion. A pericardial window was found, $7.6 \times 7.6 \mathrm{~cm}$ in size, and through this the left atrial appendage and half the left ventricle were protruding. These structures appeared inflamed and the atrial appendage had necrotic looking areas on its surface. Pressure studies confirmed the absence of a mitral valve lesion. The atrial appendage was excised. The left ventricle was returned within the pericardium after division of recent adhesions and the pericardial defect repaired with two-way stretch 'dacron'. The postoperative course was uneventful.

Histology of the atrial appendage showed fatty change extending into the muscle, oedematous connective tissue, chronic inflammatory change, interstitial haemorrhage, and a few areas of granulation tissue. No viruses or bacteria were grown from the pericardial or pleural fluid.

At the follow-up four months later the patient was asymptomatic and the white cell count and erythrocyte sedimentation rate were normal. Electrocardiogram still showed slight QRS abnormality in leads III and aVR and $T$ wave inversion in lead VI. There was, however, a striking improvement in the $T$ waves elsewhere and a pronounced decrease in the size of the $P$ waves. Chest $x$-ray showed a somewhat high left diaphragm and a less prominent protruberance.at the left cardiac border.

Seven months after operation he was well within the third percentile for weight.

\section{Discussion}

Asymptomatic herniation of the left auricle through a presumed congenital defect in the pericardium was reported by Fry (1953), the chest $x$-ray appearances being similar to those of subsequently reported cases (Chang and Leigh, 196I; KavanaghGray, Musgrove, and Stanwood, I96r; Baker, Schlang, and Ballenger, 1965) and of the present

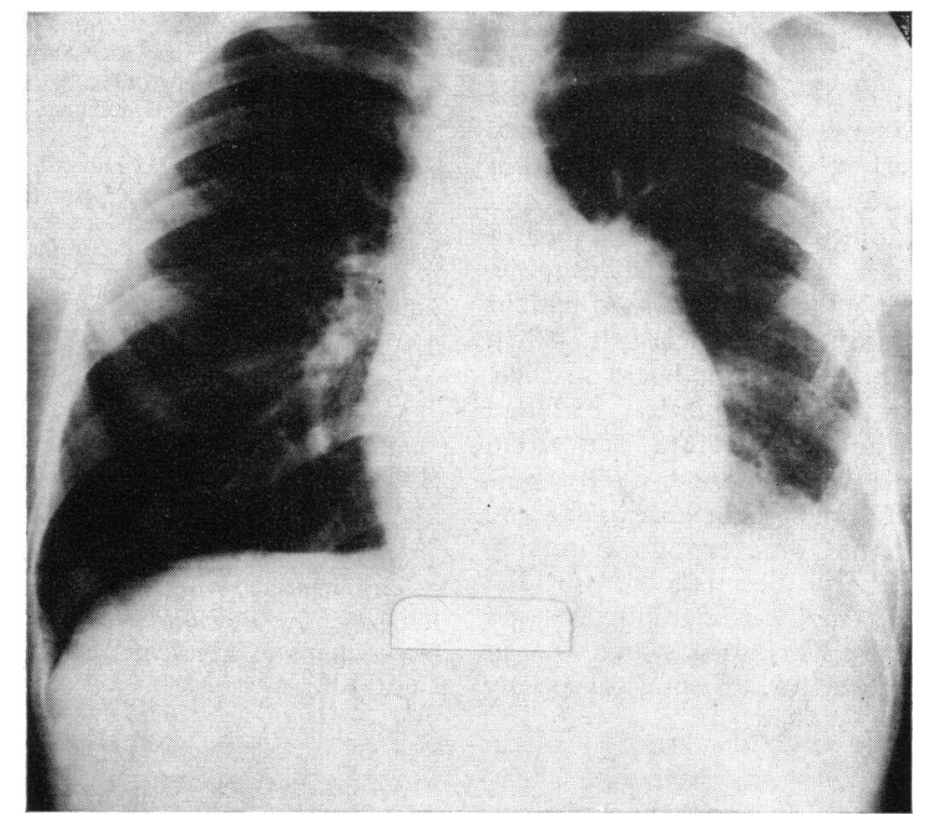

FIG. 2 Chest $\mathrm{x}$-ray on admission. 
case. A case reported by Dimond, Kittle, and Voth (1960), showed electrocardiographic abnormalities with inverted $T$ waves and a... peculiar deflection of the baseline immediately prior to the onset of the QRS' most pronounced in leads III, aVL, and aVF. This case showed hypertrophy of the herniated appendage, which was resected with subsequent return to normal of the QRS complex.

Further cases were reported by Williams (1963) who suggested that a similar picture could occur with an intact pericardium. In support of this a patient with a large intrapericardial aneurysm of the left auricle, presenting as cardiomegaly on chest $x$-ray was reported by Sanderud et al. (197I). Godwin et al. (1968) reported a similar case with recurrent arrhythmias cured by surgical resection of the appendage.

Our patient and those of Ellis, Leeds, and Himmelstein (1959), Hering, Wilson, and Ball (I960), and Tucker, Miller, and Jacoby (1963), had chest pain and our patient and those of Hering et al. (1960) and Tucker et al. (1963) had pericardial friction. Our patient was unique among survivors in having ventricular herniation in addition, though sudden death associated with ventricular herniation in such patients had been recorded (Sunderland and Wright-Smith, 1944; Tubbs and Yacoub, I968). Ventricular herniation through a surgically created pericardial defect after pneumonectomy is described, and usually produces acute cardiovascular collapse (Yacoub, Williams, and Ahmad, 1968). In our patient strangulation of the atrial appendage produced pleural effusion and a progressive deterioration of the electrocardiogram, a complication hitherto unreported. Other recorded patients had symptoms attributed to emboli from mural thrombus in the auricle (Williams, 1963), and in our view the possibility of these two types of complication made excision of the auricle desirable.

The initial differential diagnosis in our patient included all the causes of acute pericarditis. When the mass was seen in relation to the heart on chest $x$-ray, further diagnostic possibilities included tumours of the heart and pericardium, pericardial fat necrosis (Behrendt and Scannell, 1968), pulmonary embolism, and malignant disease of the lung or hilar lymph nodes. Tomography was initially helpful in suggesting the visible mass was not due to hilar lymph nodes. Angiocardiography showed that the outline contained a lumen which was in communication with the left atrium but thoracotomy was necessary for the definitive diagnosis of the anatomical lesion.

The pericardial defect which allowed cardiac herniation may well have been congenital (Arey, 1949; Tubbs and Yacoub, 1968), but it is conceivable that the road accident six years previously may have contributed to the defect or the herniation. Any relation between the cardiac lesion and the patient's stature must remain conjectural. A rapid growth spurt in the early years after operation might suggest that the two are related.

\section{References}

Arey, L. B. (1949). Developmental Anatomy. W. B. Saunders, Philadelphia and London.

Baker, W. P., Schlang, H. A., and Ballenger, F. P. (1965). Congenital partial absence of the pericardium. American fournal of Cardiology, 16, 133.

Behrendt, D. M., and Scannell, J. G. (1968). Pericardial fat necrosis. New England fournal of Medicine, 279, 473.

Chang, C. H., and Leigh, T. F. (I96I). Congenital partial defect of the pericardium associated with herniation of the left atrial appendage. American fournal of Roentgenology, $86,517$.

Dimond, E. G., Kittle, C. F., and Voth, D. W. (1960). Extreme hypertrophy of the left atrial appendage. American Fournal of Cardiology, 5, 122.

Ellis, K., Leeds, N. E., and Himmelstein, A. (1959). Congenital deficiences in the parietal pericardium. American fournal of Roentgenology, 82, 125.

Fry, W. (1953). Herniation of the left auricle. American fournal of Surgery, 86, 736.

Godwin, T. F., Auger, P., Key, J. A., and Wigle, E. D. (1968). Intrapericardial aneurysmal dilatation of the left atrial appendage. Circulation, 37, 397.

Hering, A. C., Wilson, J. S., and Ball, R. E. (1960). Congenital deficiency of the pericardium. Fournal of Thoracic and Cardiovascular Surgery, 40, 49.

Kavanagh-Gray, D., Musgrove, E., and Stanwood, D. (1961). Congenital pericardial defects. New England fournal of Medicine, 265, 692.

Sanderud, A., Garman, D., Hatle, L., and Rokseth, R. (I97I). Aneurysmal dilatation of the left auricle. Scandinavian Fournal of Thoracic and Cardiovascular Surgery, 5, 143.

Sunderland, S., and Wright-Smith, R. J. (1944). Congenital pericardial defects. British Heart fournal, 6, 167.

Tubbs, O. S., and Yacoub, M. H. (I968). Congenital pericardial defects. Thorax, 23, 598.

Tucker, D. H., Miller, D. E., and Jacoby, W. J. (1963). Congenital partial absence of the pericardium with herniation of the left atrial appendage. American fournal of Medicine, 35, 560 .

Williams, W. G. (1963). Dilatation of the left atrial appendage. British Heart fournal, 25, 637.

Yacoub, M. H., Williams, W. G., and Ahmad, A. (I968). Strangulation of the heart following intrapericardial pneumonectomy. Thorax, 23, 261 .

Requests for reprints to Professor M. S. Losowsky, Department of Medicine, St. James's Hospital, Leeds LS9 7 TF. 